\title{
Effects of 10-Week Body Stability Exercise Program on Functional Movement and Body Balance of Middle School Volleyball Players
}

\author{
In-Yeong Song, Yeon-Soon Seo, Yang-Hoon Kang \\ Department of Physical Therapy, College of Health Science, Mokpo Science University, Mokpo, Republic of Korea
}

\begin{abstract}
Purpose: This study examined the effects of a physical stability exercise program on the functional movement and balance of middle school volleyball players to provide future management and training data to improve the performance of volleyball players.

Methods: The subjects were 20 volleyball players from Y Middle School in Mokpo. The results of comparing and analyzing the effects of the physical stability exercise program on the functional movement and balance of middle school volleyball players for 10 weeks are as follows.

Results: The number of participants who showed power and agility $(p<0.01)$ was increased significantly, and the response time was shortened significantly $(p<0.01)$. On the evaluation of functional movement, the total score showed a significant difference between the pre-test at $10.90 \pm 1.30$ points and the post-test at $13.81 \pm .60(p<0.001)$. The subjects' balance showed a significant difference from $84.11 \pm 7.53$ to $97.65 \pm 8.47(p<0.001)$, and the Right Composite Score showed a significant difference from $83.74 \pm 6.64$ to $97.27 \pm 8.48$ $(p<0.001)$.
\end{abstract}

Conclusion: The application of a physical stability exercise program for 10 weeks is effective in improving the speed, agility, functional movement, and balance to volleyball players who are weakened and at risk of injury. This is believed to prevent or reduce injury.

Keywords: Power, Agility, Functional movement, Body balance

\section{서 론}

배구는 점프, 스파이크 그리고 블로킹 시 폭발적인 파워를 필요로 하 는 팀 스포츠라고 정의할 수 있다. 배구경기는 다양한 동작과 기술 을 짧은 시간 내 반복적으로 수행하여 높은 체력수준이 요구되고 근 력, 민첩성, 균형능력을 요구하는 종목이다. 배구 선수의 경우 한 경기 당 250-300회의 점프를 하기 때문에 높은 수준의 하지 근력과 순발력 이 필요하다. 배구경기는 선수들의 반응시간이 빨라야 하고, 순간적 으로 강한 힘을 필요로 하며, 잦은 수직점프 동작으로 인해 부상이 잦은 종목이다. 점프 후 착지는 중력에 의해 피할 수 없는 과정으로 써 하지 관절의 부상과 밀접한 관련이 있는 동작이고, 배구 경기에서 수없이 반복되는 동작이며, 점프 높이의 증가는 부상의 위험성을 높 인다. 더불어 점프의 거리에 대해 Marquez 등 5 은 인체 중심의 수직 및 수평 방향의 속도를 증가시켜 착지 시점에서의 기계학적 자세에
영향을 미치고, 무릎과 엉덩관절의 굽힘 움직임을 감소시킴으로써 최대 수직 지면반발력과 부하율을 증가시킨다고 보고하였다. 이처럼 점프의 높이뿐만 아니라 거리 또한 충격을 증가시켜 부상을 높이는 중요한 요소라고 할 수 있다. 따라서 배구선수의 경기력을 관리 및 유 지하기 위해서는 신체조성과의 관련성을 상세히 검토할 필요가 있다. 신체가 기능적인 움직임을 할 때, 상지와 하지로부터 힘을 만들어 내 거나 그것을 전이시키는 능력을 최적화시키기 위해서는 몸통의 자세 와 움직임을 조절하는 능력이 필요하다. ${ }^{6}$

체간은 균형을 유지하면서 중력에 대하여 독립된 자세를 유지하 고 사지의 움직임을 대비하는 자세적 역할과 중심이동을 원활히 하 여 새로운 자세로 쉽게 움직이도록 하는 동적인 역할을 수행한다. 신 체안정화는 신체중립을 유지하는 안정화 체계의 유의한 능력이라고 할 수 있으며, 수동적 움직임, 능동적 움직임, 신경계 사이의 상호작용 에 의해 영향을 받게 된다. 수동적 움직임은 척추체, 추간판, 추간관 
절, 관절낭과 인대들로 주로 관절가동범위의 끝범위에서 운동을 제 한하여 안정성을 담당한다. 능동적 움직임은 척주를 둘러싸면서 작 용하는 근육과 건에 의해 제공되는 능동적이고 역동적인 지지를 담 당하여 관절에 가해지는 부하를 감소시키고, 척추에 직접 부착되어 있는 국소근육들이 중립위 범위 내에서 분절의 안정성을 유지하는 데 가장 큰 역할을 수행한다. 신경계는 고유수용성 감각기관들과 중 추신경계로 구성되는 신경적 안정화이다. 이러한 신체안정화는 근 력과 균형에 영향을 주며 운동선수에게 매우 중요한 요소이다. 신체 안정화운동은 체간을 안정시키기 위해 코어근육을 동시에 훈련시키 는 운동으로 불안정한 자세 유지 및 조절능력을 증진시키는데 효과 적이다. ${ }^{10}$

선행연구에 의하면 일정 기간의 신체안정성 훈련은 운동선수의 체 력을 유의하게 향상시킬 수 있는 것으로 보고되었는데, Sharma 드ㅇㅣㅡㅡㄴ 배구선수를 대상으로 9주간 코어훈련을 적용하게 했을 때, 신체안정 성과함께 수직 점프능력이 증가되었다고 보고하였다. Myer 등른 코 어가 포함된 6 주간의 훈련은 여자 운동선수의 운동수행력과 함께 하 지의 움직임과 관련된 역학적 요인을 향상시켰다고 보고하였다. 이와 같이 신체안정화운동이 효과적이라는 사실이 이미 밝혀졌지만, 이러 한 훈련방법을 적용하여 여자 배구선수를 대상으로 기능적 움직임 과 균형능력에 미치는 영향을 검토한 연구는 미비한 실정이다.

따라서 본 연구에서는 10 주간 신체안정성 운동프로그램이 중학교 배구선수의 기능적 움직임과 균형에 어떠한 영향을 미치는지 규명하 고, 신체안정성 운동프로그램을 적용함으로써 배구 선수들의 경기력 향상을 위한추후 관리 및 훈련 자료를 제공하는데 목적이 있다.

\section{연구 방법}

\section{1. 연구 대상}

본 연구의 대상자는 목포시 Y중학교 배구선수 20명을 대상으로 구성 하였고, 모든 피험자들에게 검사 전반에 대한 설명과 측정에 대한 정 보를 충분히 알린 후 측정을 실시하였다. 연구대상자의 신장을 측정 하기 위해 자동 신장측정기(DS-103, Dong Sahn Jenix, Korea)를 이용하 였고 체중과 체지방률의 측정은 생체전기 임피던스 장비(InBody

Table 1. General characteristics of participants

\begin{tabular}{lr}
\hline Characteristics & \multicolumn{1}{c}{ Value } \\
\hline Age $(\mathrm{yr})$ & $15 \pm 0.94$ \\
Height $(\mathrm{cm})$ & $168.43 \pm 6.36$ \\
Weight $(\mathrm{kg})$ & $56.11 \pm 3.28$ \\
BMI $\left(\mathrm{kg} / \mathrm{m}^{2}\right)$ & $19.80 \pm 1.18$ \\
Body fat $(\%)$ & $30.90 \pm 2.77$ \\
Leg length $(\mathrm{cm})$ & $92.83 \pm 5.82$ \\
\hline
\end{tabular}

$\mathrm{H} 20$, InBody, Korea)를 이용하였으며 측정한 연구대상자의 일반적 특 성은 다음과같다(Table 1).

\section{2. 신체 안정화 운동 방법}

신체안정화 운동은 $\mathrm{McGill}$ 과 Karpowicz ${ }^{13}$ 가 시행한 신체안정화운동 을 적용하여 10 가지 동작으로 구성되었고, 한 동작당 12초씩 유지하 도록 지시하였다. 한 동작당 10 회씩 반복하여 총 2-3세트 훈련을 실시 하였고, 1 회 실시 후 5 초간의 휴식시간을 두어 실시하였다. 신체안정 화운동의 난이도는 실험 4 주 후 운동 지지면을 불안정하게 하여 난 이도를 조정하였다. 실험은 총 10 주간, 주 3 회, 30 분간 실시하였고, 신 체안정화 운동프로그램 적용 전 5 분간의 준비운동 시간을 두고 훈련 을 실시하였다(Table 2). ${ }^{14}$

\section{3. 측정항목 및 분석방법}

본 연구는 신체안정성 운동프로그램이 배구선수의 기능적 움직임과 균형에 미치는 영향을 살펴보기 위해 모든 피험자들에게 프로그램 적용 전 시각반응속도 측정, 기능적 움직임 평가(FMS), 신체균형능력 평가(Y-Balance) 등 개별평가를 실시하고, 10 주간의 신체안정성 운동 프로그램을 실시하여, 프로그램 적용 후 사후 평가를 실시하였다. 또 한 검사 전 보호자와 대상자에게 연구에 대한 충분한 사전 설명과 실 험 동의 여부를 확인하였다.

\section{1) 시각반응속도 측정}

시각반응속도는 BlazePod (Play coyotta Ltd., Thailand)를 사용하여 측 정하였고, 이것은 순간 스피드, 반사신경 등의 특수한 능력을 측정할 수 있는 장비이다. 전문화된 반사 신경 및 순발력을 길러주는 순간 반 사 운동(Flash Reflex Exercise, FRX)을 기반으로 만들어졌고, 시각반 응속도 측정 전용 앱을 통해 자신의 기록을 정확하게 확인할 수 있 다. 본 연구에서는 신체안정화 운동 프로그램 적용 전과 후에 측정장 비를 적용하여 시각반응속도를 측정하였다. 시각반응속도 측정장비

Table 2. Body stability exercise program

신체안정화 운동프로그램(body stability exercise program)

1. 머리, 가슴 들기(Curl-up)

2. 바로 누워 교차로 팔 다리 들기(Dead Bug)

3. 바로 누워 몸통 들기(Supine bridge)

4. 옆으로 누워 몸통 들기(Sidelying Bridge)

5. 엎드려 누워 몸통 들기(Prone Bridge)

6. 심부근육 수축운동(Abdominal Bracing)

7. 네발기기 자세에서 교차로 팔 다리 들기(Quadruped)

8. 네발기기 자세에서 교차로 들어올린 팔 다리로 사각형 그리기(Modified Quadruped)

9. 엎드려 누워 교차로 팔 다리 들기(Swimming)

10. 엎드려 누워 같은 쪽 팔 다리 들기(Modified Swimming) 
에 불빛이 들어오면 터치하는 방식으로 15 초 동안 터치한 횟수와 15 초 동안 터치하는 것으로 정해진 시간동안 시각반응에 대한 반응횟 수와 시각에 의한 반응시각을 확인할 수 있다. 상지의 측정을 엎드린 상태를 유지한 상태에서 측정하였고 동일하게 측정할 수 있도록 위 치가 표시된 매트를 이용하였고 하지는 선 상태에서 양쪽을 측정하 였고 3 회 측정하여 평균값을 사용하였다.

\section{2) 기능적 움직임 평가}

기능적 움직임 평가(Functional Movement Screen)는 Cook 등의 연구 를 참고하여 진행되었으며, 검사를 위해 전용 키트(Functional Movement Screen Test Kit, Functional Movement Systems Inc., USA)가 사용 되었다. ${ }^{15}$ 기능성 움직임 평가는 Deep squat부터 Hurdle step, In-line lunge, Shoulder mobility, Active straight leg raise, Trunk stability push-up 그리고 Rotary stability까지 총 7가지 항목으로 구성되어 있다. 본 연구 에서는 피험자에게 평가 방법에 대해 충분히 설명하였고, 왼쪽과 오 른쪽을 평가하는 테스트는 기본지침에 따라 왼쪽부터 실시하였으 며, 최종 결과에서 가장 적게 나온 점수를 기록하였다. FMS의 점수는 완벽한 동작을 수행함(3점), 동작을 실행하나 완벽하지 못함(2점), 동 작 수행을 하지 못함(1점), 통증이 있음(0점)으로 총 21점 만점에 0-3 점의 순위 척도로 구성되었다. FMS-kit를 사용하여 측정하였으며, FMS 측정의 정확도를 높이기 위하여 공통된 측정방법을 사전에 교 육 받았으며 철저하게 숙지한 3 명의 평가자가 2 명은 측정 시 실시간 관찰하면서 평가하고 FMS를 점수화시켰다. 결과의 신뢰성 확보를 위 하여 1 명은 정확한 기록과 동시에 카메라를 이용하여 녹화하였고 측 정 후 녹화된 내용을 다시 시청하면서 검토를 진행하였다.

\section{3) 신체균형능력 평가}

Composite Score $=\frac{(\text { Anterior }+ \text { Posteriomedial }+ \text { Posteriolateral }) \times 100}{(3 \text { Limb Length })}$

신체균형능력(Y-Balance) 평가는 자세조절과 발목의 안정화를 동 시에 검사할 수 있는 방법이다. 본 연구에서는 피험자에게 플랫폼에 서 발이 유지되지 못하거나 발이 떨어지지 않도록 측정방법 및 주의
사항을 설명한 후 양쪽 발 모두 각각 3 회 실시하였다. 측정 시에는 신 발을 벗고 실시하였으며 중심을 잃은 경우, 다시 처음의 시작자세로 돌아오지 못하는 경우 그리고 발이 땅에 닿거나, 발판을 발로 차는 경우에는 파울로 간주하였다. ${ }^{15}$ 신체균형능력 평가에서는 앞쪽(anterior), 뒤-안쪽(posteriomedial), 뒤가쪽(posteriolateral)의 수치를 모두 더한 값을 피험자의 다리길이(limb length)를 3 배수 곱한 값으로 나누 고 100을 곱하여 총합 점수(composite score)로 분석하였다. 피험자의 다리길이는 전상장골극(anterior superior iliac spine, ASIS)에서 안쪽복 사뼈(medial malleolus)까지의 거리로 하였다.

\section{4. 자료처리}

본 연구에서 얻어진 자료는 SPSS 21.0 for Window 통계 프로그램을 통 해 기술통계를 이용하여 평균과 표준편차를 산출하였고, 정규성 검 정을 시행하였다. 정규성을 만족한 신체안정화운동에 따른 변인들의 사전, 사후 효과성을 검정하기 위해 모수 검정법인 대응표본 $\mathrm{t}$ 검정 (paired t-tast)을 실시하였고, 통계적 유의수준은 $\alpha=0.05$ 로 설정하였다.

\section{결 과}

\section{1. 시각반응속도의 변화}

배구선수에게 적용한 10 주간 신체 안정화 훈련이 시각반응속도에 영향을 미치는지에 대한 결과는 다음과 같다. 상지의 15 초 동안 터치 는 사전 $18.48 \pm 5.29$ 회, 사후 $20.05 \pm 5.47$ 회로 유의한 차이를 보였고 $(\mathrm{p}<0.01)$, 상지의 반응시간은 사전 $845.90 \pm 225.52 \mathrm{~ms}$, 사후 $763.43 \pm$ $190.64 \mathrm{~ms}$ 로 반응시간이 유의하게 짧아지는 결과를 보였다 $(\mathrm{p}<0.01)$. 왼쪽 하지의 15 초 동안 터치는 사전 $21.05 \pm 3.30$ 회, 사후 $22.90 \pm 2.91$ 회 로 유의한 차이를 보였고 $(\mathrm{p}<0.01)$, 왼쪽 하지의 반응시간은 사전 $791.67 \pm 343.63 \mathrm{~ms}$, 사후 $641.14 \pm 88.94 \mathrm{~ms}$ 로 반응시간이 유의하게 짧 아지는 결과를 보였다 $(\mathrm{p}<0.05)$. 오른쪽 하지의 15 초 동안 터치는 사전 $21.95 \pm 2.76$ 회, 사후 $23.29 \pm 2.98$ 회로 유의한 차이를 보였고 $(\mathrm{p}<0.01)$, 오 른쪽 하지의 반응시간은 사전 $669.86 \pm 97.62 \mathrm{~ms}$, 사후 $632.86 \pm 91.43$ $\mathrm{ms}$ 로 반응시간이 유의하게 짧아지는 결과를 보였다 $(\mathrm{p}<0.01)(T a b l e 3)$.

Table 3. Effects of 10-week body stability exercise program on power and agility

(unit: times, ms)

\begin{tabular}{|c|c|c|c|c|c|}
\hline Factor & & Pre & Post & $\mathrm{t}$ & $\mathrm{p}$ \\
\hline \multirow[t]{2}{*}{ Upper extremity } & Touch for 15 seconds & $18.48 \pm 5.29$ & $20.05 \pm 5.47$ & -3.766 & $0.001^{* * *}$ \\
\hline & Reaction time (ms) & $845.90 \pm 225.52$ & $763.43 \pm 190.64$ & 3.937 & $0.001^{* * *}$ \\
\hline \multirow[t]{2}{*}{ Left Lower extremity } & Touch for 15 seconds & $21.05 \pm 3.30$ & $22.90 \pm 2.91$ & -3.914 & $0.001^{* * *}$ \\
\hline & Reaction time (ms) & $791.67 \pm 343.63$ & $641.14 \pm 88.94$ & 2.372 & $0.028^{* *}$ \\
\hline \multirow[t]{2}{*}{ Right Lower extremity } & Touch for 15 seconds & $21.95 \pm 2.76$ & $23.29 \pm 2.98$ & -3.765 & $0.001^{* * *}$ \\
\hline & Reaction time (ms) & $669.86 \pm 97.62$ & $632.86 \pm 91.43$ & 2.996 & $0.007^{* * *}$ \\
\hline
\end{tabular}

${ }^{* * *} p<0.01,{ }^{* *} p<0.05$ 


\section{2. 기능적 움직임의 변화}

배구선수의 10 주간 신체안정화 훈련이 기능적 움직임에 영향을 미치 는지에 대한 결과는 다음과 같다. Deep Squat는 사전 $1.76 \pm 0.43$ 점, 사 후 $2.10 \pm 0.30$ 점으로 유의한 차이의 결과를 보였고 $(\mathrm{p}<0.01)$, Hurdle Step은 사전 $1.86 \pm 0.36$ 점, 사후 2.00점으로 차이를 나타내지 않았다. In-Line Lunge는 사전 $1.52 \pm 0.51$ 점, 사후 2.00 점으로 유의한 차이의 결 과를 보였고 $(\mathrm{p}<0.001)$, Shoulder Mobility는 사전 $1.62 \pm 0.49$ 점, 사후 $1.86 \pm 0.35$ 점으로 유의한 차이의 결과를 보였다 $(\mathrm{p}<0.05)$. Active Straight Leg Raise는 사전 $1.62 \pm 0.49$ 점, 사후 $1.95 \pm 0.21$ 점으로 유의한 차이의 결과를 보였다 $(\mathrm{p}<0.01)$. Trunk Stability Push-Up은 사전 $1.10 \pm$ 0.30 점, 사후 $1.95 \pm 0.21$ 점, Rotary Stability는 사전 $1.43 \pm 0.50$ 점, 사후 $1.95 \pm 0.21$ 점, Total Score는 사전 $10.90 \pm 1.30$ 점, 사후 $13.81 \pm 0.60$ 점으로 유의한 차이의 결과를 보였다 $(\mathrm{p}<0.001)($ Table 4$)$.

\section{3. 신체균형능력의 변화}

배구선수의 10 주간 신체 안정화 훈련이 신체균형능력에 영향을 미치 는지에 대한 결과는 다음과 같다. Left Composite Score는 사전 84.11 7.53점, 사후 $97.65 \pm 8.47$ 점으로 유의한 차이의 결과를 보였고 ( $\mathrm{p}<0.001)$, Right Composite Score는 사전 83.74 \pm 6.64점, 사후 97.27 \pm 8.48 점으로 유의한 차이의 결과를 보였다 $(\mathrm{p}<0.001)$ (Table 5).

Table 4. Effects of 10-week body stability exercise program on functional movememt

(Unit: score)

\begin{tabular}{lcccc}
\hline Factor & Pre & Post & $\mathrm{t}$ & $\mathrm{p}$ \\
\hline Deep squat & $1.76 \pm 0.43$ & $2.10 \pm 0.30$ & -3.162 & $0.005^{* *}$ \\
Hurdle step & $1.86 \pm 0.36$ & 2.00 & -1.826 & 0.083 \\
In-Line lunge & $1.52 \pm 0.51$ & 2.00 & -4.264 & $<0.001^{* * *}$ \\
Shoulder mobility & $1.62 \pm 0.49$ & $1.86 \pm 0.35$ & -2.500 & $0.021^{*}$ \\
Active straight leg raise & $1.62 \pm 0.49$ & $1.95 \pm 0.21$ & -3.162 & $0.005^{* *}$ \\
Trunk stability push-up & $1.10 \pm 0.30$ & $1.95 \pm 0.21$ & -10.954 & $<0.001^{* * *}$ \\
Rotary stability & $1.43 \pm 0.50$ & $1.95 \pm 0.21$ & -4.690 & $<0.001^{* * *}$ \\
Total score & $10.90 \pm 1.30$ & $13.81 \pm 0.60$ & -10.238 & $<0.001^{* * *}$
\end{tabular}

${ }^{* * *} p<0.001,{ }^{* *} p<0.01,{ }^{*} p<0.05$
고 찰

배구경기는 전문적인 체력을 바탕으로 수행되는 종목으로 기 본과 응용기술은 전문체력의 완성도에 의해 결정되며, 배구 기 술은 아주 정교하고 감각적인 운동으로 기본기술이 안정화되 지 못할 경우 전문적인 체력을 활용할 수 없게 된다. 이에 배구 종목의 전문체력은 기술동작과 직접적인 상관성을 가져야 하 는 특이적 훈련방법이 필요하며, 높은 운동수행능력과 스포츠 손상을 예방할 수 있는 훈련방법이 요구되고 있다. 신체안정성 은 신체에 나타나는 자극과 반응을 연결하고 상. 하체의 협응 을 유도하므로, 배구경기 중 빈번한 수직점프의 수준을 결정하 는 요인으로 여겨진다. 특히 배구 경기 중 스파이크 동작은 하 지의 근력과 어깨관절의 동적 움직임이 협응되는 동작이므로, 신체안정성의 중요성이 강조된다. 또한 체간근육은 체공시간 을 증가시키기 때문에 공중에 띄워진 공을 처리하는 스파이크 동작에서 공격력을 확보하는데 도움이 되기도 한다. ${ }^{17}$

본 연구에서는 배구선수의 10 주간 신체안정화 훈련이 시각반응속 도 변화에 영향을 미치는지에 대한 결과 전반적으로 신체안정화 운 동 이후로 15 초 동안의 터치한 횟수가 유의하게 증가하였고, 15 초 동 안의 반응시간도 유의하게 짧아졌고, 배구선수에게 요구되는 순발 력, 민첩성 그리고 협조성과 같은 기술체력을 유의하게 향상시킨 것 으로 나타났다.

선행연구에서 Choi 등 18 은 체육전공 남학생 24명을 대상으로 8 주 간의 웨이트 트레이닝과 플라이오메트릭 트레이닝(Plyometric training)이 민첩성 및 등속성 근력에 미치는 영향에 대한 연구를 하였다. 그 결과 민첩성에서 유의하게 향상되었으며, 등속성 근력과 근파워 에서도 긍정적 효과가 있는 것으로 나타났다. $\mathrm{Na}^{19}$ 는 남자축구선수 30 명을 대상으로 12 주간의 플라이오메트릭 트레이닝 이 하지근력 및 순발력, 민첩성에 미치는 영향에 대한 연구를 하였다. 그 결과 하지근 력과 축구경기력 향상에 지대한 역할을 하는 민첩성과 순발력에도 긍정적인 결과가 나타났다.

Table 5. Effects of 10-week body stability exercise program on body balance

(Unit: score)

\begin{tabular}{|c|c|c|c|c|c|}
\hline Factor & & Pre & Post & $\mathrm{t}$ & $\mathrm{p}$ \\
\hline \multirow[t]{4}{*}{ Left } & Anterior $(\mathrm{cm})$ & $56.90 \pm 6.09$ & $64.67 \pm 7.07$ & -10.183 & $<0.001^{* * *}$ \\
\hline & Posteriolateral (cm) & $87.05 \pm 9.85$ & $100.90 \pm 6.60$ & -17.163 & $<0.001^{* * *}$ \\
\hline & Posteriomedial (cm) & $89.62 \pm 6.36$ & $105.48 \pm 6.73$ & -18.425 & $<0.001^{* * *}$ \\
\hline & Composite score & $84.11 \pm 7.53$ & $97.65 \pm 8.47$ & -15.543 & $<0.001^{* * *}$ \\
\hline \multirow[t]{4}{*}{ Right } & Anterior (cm) & $56.62 \pm 7.28$ & $63.90 \pm 8.14$ & -9.585 & $<0.001^{* * *}$ \\
\hline & Posteriolateral (cm) & $86.81 \pm 6.80$ & $102.71 \pm 7.61$ & -18.594 & $<0.001^{* * *}$ \\
\hline & Posteriomedial (cm) & $89.24 \pm 6.18$ & $103.38 \pm 7.88$ & -17.211 & $<0.001^{* * *}$ \\
\hline & Composite score & $83.74 \pm 6.64$ & $97.27 \pm 8.48$ & -15.842 & $<0.001^{* * *}$ \\
\hline
\end{tabular}

$* * * p<0.001$ 
Vaczi 등 20 은 반응속도는 점프, 달리기, 정지, 방향 전환 및 측면 움 직임 같은 동적 움직임은 스포츠 현장에서 중요한 성공 요소이며, 이 러한 개인 요소는 팀 전술과 전력에 크게 기여한다고 보고하였다. 반 응속도의 변화는 경기력 향상에 매우 중요한 요소로 짧은 순간 근육 이 폭발적으로 수축할 때의 힘을 의미하고, 힘과 속도를 조절하기 위 해서는 신체 안정화가 필요하다. 이러한 결과는 신체안정화 운동이 근수축과 신경전달기능을 향상시키고, 근육의 힘이 강해지고 인대 나 건을 신장시키는 고유 감각 기능을 촉진시켰기 때문이라고 생각 된다. 또한 신체안정화로 인하여 어깨와 팔, 그리고 다리 근육의 사용 을 효율적으로 개선시켰기 때문에 단시간에 강한 힘을 발휘해야 하 는 최대 파워의 수행에 있어서 도움을 주었고, 이러한 특성은 순간적 인 방향전환을 반복적으로 수행해야 하는 민첩성과 같은 기술체력 항목에서 기록을 단축시킬 수 있었던 것으로 사료된다.

본 연구에서는 배구선수의 기능성 움직임 평가 점수가 유의하게 향상된 것으로 나타났다. 신체안정성 운동을 하기 전에는 기능성 움 직임 평가의 평균 점수가 $10.90 \pm 1.30$ 점으로 선행연구들에서 제시한 기준 점수보다 아래에 있었다. 그러나 신체안정성 운동을 적용한 후 기능성 움직임 검사의 총점이 훈련 이후 $13.81 \pm 0.60$ 점으로 향상된 것 을 볼 수 있었다. 이러한 결과는 신체안정화에 사용되는 체간근육이 동적움직임 시 2 차로 하지의 움직임이 발생하여 근력강화에 영향을 주었다고 판단되며, Arokoski 등르는 체간근육의 효율적인 기능수행 과 요부근의 강화는 상하지의 효율적인 기능 수행에 도움을 준다고 보고하였는데 본 연구결과를 뒷받침하고 있다. 몇몇 연구에서 기능 성 움직임 평가의 총점이 14점 이하일 때, 부상의 발생 가능성이 높은 것으로 보고된 만큼, 기능성 움직임이 저하되었을 때에는 부상으로 이어질 확률이 크다는 것을 예측해 볼 수 있다. ${ }^{22,23}$ 선행연구에서 Chapman 등 24 은 시즌 전 FMS를 실시한 이후 한 시즌간의 운동수행 력 변화를 관찰했을 때, 14 점 이상의 높은 점수를 얻은 육상선수가 14 점 이하의 낮은 점수를 얻은 육상선수보다 운동수행력에서 유의 한 차이를 나타냈으며, FMS를 통해 불균형이 나타나지 않았던 육상 선수는 불균형이 있는 선수에 비해 운동 수행력이 장기간 향상되었 다고 보고하였고, FMS 평가를 통해 부상의 예방이나 감소뿐 아니라 경기력의 향상을 예측하는 검사로 활용할 수 있음을 제시하였다. 또 한, Yoon 등 25 은 볼링선수 8 명을 대상으로 8 주간 집중 척추 안정화 운 동을 통해 FMS와 하지 근기능의 효과를 검증한 결과 FMS에서는 Deep Squat에서 유의한 차이가 나타났고 $(\mathrm{p}<0.01)$, 또한 Hundle Step, Inline Lunge에서도 유의한 차이가 나타났으며 $(\mathrm{p}<0.05)$, 하지 근기능 의 각속도에서 유의한 차이가 나타났다고 보고하였다. Jung ${ }^{26}$ 은 남자 육상선수 16 명을 대상으로 12 주간 복합트레이닝이 중학교 육상 단거 리선수의 체력 및 FMS 결과에 미치는 영향에 대한 연구를 하였는데, 복합트레이닝은 육상 선수들에게 체력 및 FMS 결과를 향상시킨다고
보고하였다. 근력의 향상은 기능적 움직임 평가에서 확연하게 향상 되는 것을 볼 수 있는데, 본 연구 결과 기능적 움직임 항목 중 deep squat 외 각각의 항목에서 향상되는 것으로 나타났다. Lockie 등 ${ }^{27}$ 의 연구에서는 deep squat와 hurdle step의 기능적 움직임의 향상은 선수 들의 다리근력을 향상시키며, 특히 전력질주(sprinting)와 점프(jumping)능력을 증가시킨 것으로 보고하였다. David 등 ${ }^{28}$ 의 연구에서 축구 선수들의 deep squat와 hurdle step의 향상은 무릎과 엉덩이 부상을 감 소시킨다고 하였다. Tori와 $\operatorname{Susan}^{29}$ 의 연구에서도 deep squat의 기능적 움직임 향상은 발목, 무릎 및 골반의 움직임 향상을 유도할 것이라고 보고하였다. 그래서 신체안정성 근육이 제대로 확보되지 않았다면 기능성 움직임 검사에서 좋은 점수를 받기가 어려웠을 것이다. 따라 서, 신체의 기능이 저하되어 있는 배구선수에게 일정 기간의 신체안 정성 운동은 기능성 움직임 검사 점수를 향상시키는데 있어서 효과 적이고, 이는 곧 부상의 예방이나감소로도 이어질 수 있을 것으로 사 료된다.

본 연구에서는 배구선수의 10 주간 신체안정화 훈련이 신체균형능 력에 영향을 미치는지에 대한 결과에서 Left Composite Score는 사전 $84.11 \pm 7.53$ 점, 사후 $97.65 \pm 8.47$ 점으로 유의한 차이를 보였고, Right Composite Score는 사전 $83.74 \pm 6.64$ 점, 사후 $97.27 \pm 8.48$ 점으로 유의한 차이를 보였다. 이러한 결과는 신체안정성의 개선으로 체간과 복부 근육군인 코어근육이 단련되어 체간부의 근력과 유연성을 향상시킬 수 있었으며, 신체 균형을 유지하는 동적평형성에도 긍정적인 영향 을 미친 것으로 보인다.

선행연구에서 Sharma 등1은 배구선수를 대상으로 동적 안정화 운 동프로그램을 실시한 결과, 수직점프 및 정적 균형능력이 향상되었 고, 감속 동작인 착지 시 하지 근력의 증가는 하지 관절의 상해 위험 률을 감소시킬 수 있을 것으로 보고하였다. 또한, $\operatorname{Park}^{30}$ 은 코어 밸런 스 운동은 배구선수의 몸통 등속성 근기능과 균형능력 및 자세 안정 화에 도움이 되며, 배구경기의 안정화된 자세와 균형 잡힌 동작을 통 한 기술적 능력과 점프 동작과 스파이크 동작의 자세조절 능력이 조 화를 이루어야 우수한 경기력을 발휘 할 수 있을 것으로 생각된다고 보고하였다. 그러므로 배구선수들의 하지 근력의 좌, 우 균형성은 점 프와 착지 동작과 관련성이 있을 것으로 판단된다. Choi 등1은 12 주 간의 코어트레이닝이 여자배구선수들의 하지 근기능, 평형성, 기초체 력에 미치는 영향에 대해 살펴본 결과 오른쪽 무릎관절 근기능, 동적 균형능력, 그리고 악력, 하지 근지구력, 민첩성 등의 기초체력 등에도 긍정적인 영향을 미친 것으로 보고하였다. 또한 Noh 등 ${ }^{32}$ 은 동적인 코 어트레이닝은 체간 및 요부의 근력을 향상시켜 하지와 상지의 안정 화를 통하여 낮은 자세를 유지할 수 있게 하여 수비 동작에서 정확한 리시브를 할 수 있고, 공격에서는 스파이크 동작에서 팔과 어깨의 근 력만을 사용하지 않고 몸통의 근력을 사용하여 강한 스파이크를 칠 
수 있는데 도움을 줄 것이며, 스파이크 후 안정적인 자세로 착지할 수 있어 부상을 방지하는데 도움이 될 것이라고 보고하였다.

Casselbrant 등 33 은 평형성이 여러 경로로 입력된 감각 자극들을 통 합함으로써 신체의 모든 자세조절을 계획하고 실행한다고 하였고, 평형성이 일상생활이나 스포츠현장에서 균형 및 안정상태를 유지하 며 신체를 조정하고 통제하는 협응력에 의해 좌우된다고 하였다. 선 행연구에 의하면, $\mathrm{Ha}$ 와 Jeon ${ }^{34}$ 은 골반 경사의 정렬은 신체안정성, 균 형에 영향을 미치며, 척추의 정렬에 직접적으로 영향을 줄 수 있다고 보고하였다. 또한, Yong과 Park ${ }^{35}$ 은 경미한 다리 길이의 불일치는 짧 은쪽 다리의 고관절 굴곡과 외전, 골반 경사가 감소하고, 긴쪽 다리의 고관절 내전과 골반경사가 증가였다고 보고하였고, Lee 등 36 은 이러 한 불균형이 족압과 균형에 부정적인 영향을 끼친다고 보고하였다. 그리고, Choi 등 ${ }^{37}$ 은 좌우 몸통근육의 비대칭적인 수축양상은 통증 발생 위험이 높아질 뿐만 아니라 효과적인 척추 안정성에 부정적인 영향을 미칠 수 있다고 보고하였다. 이러한 결과를 보면 신체 불균형 과 하지 근력의 차이는 하지 관절의 부상을 높게 만드는 요인으로 작 용할수 있을 것이다.

근육의 불균형은 스포츠 상해에서 언급되는 가장 일반적이며 내 재적인 요소 중의 하나이고, 근력의 기능적 매개변수를 평가하는 것 은 상해 예방 프로그램의 디자인에 있어 매우 중요한 요소가 될 수 있 을 것이다. 하지의 무릎관절의 길항근과 주동근 사이의 근력의 비율 은 하지의 안정성에 매우 중요한 요인으로서, 안정적 근력비율은 경 기력 뿐만 아니라 무릎관절의 부상 예방에도 도움을 주는 것으로 보 고되고 있다. ${ }^{38}$ 특히 배구는 넙다리근과 무릎굴곡근이 달리기와 점 프 같은 중요한 운동능력에 관여하고 있으며, 대부분의 하지 움직임 은 양쪽으로 행해지는 강한 근수축을 필요로 한다. 따라서 하지 한 쪽의 움직임에 더욱 의존하는 스포츠 종목과 달리 배구는 양쪽 하지 의 균형적인 근력 발달이 중요하기 때문에 양쪽 하지의 근력 차이가 적어야 될 것이다.

위의 결과를 종합해 볼 때 신체의 기능이 저하되어 있는 배구선수 에게 일정 기간의 신체안정화 운동은 시각반응속도, 기능성 움직임, 신체균형능력을 향상시키는데 있어서 효과적이었다. 안정화 운동은 배구선수의 균형능력과 자세안정성 및 경기력에 도움이 되며, 배구 선수의 안정화된 자세와 균형 잡힌 동작을 통한 기술적 능력이 조화 를 이루어야 우수한 경기력을 발휘 할 수 있을 것으로 생각된다. 본 연 구의 제한점으로 대조군 없이 연구가 이루어져 일부 요인부분들을 통제할 수 없었다는 것이 제한요인으로 보이며 향후 추가 연구를 통 해 실제적으로 배구선수의 부상 예방이나 감소에 얼마나 기여할 수 있을지에 대한 부분은 장기적으로 관찰할 수 있는 연구가 요구되어 진다.

\section{ACKNOWLEDGEMENTS}

이 논문은 2020 학년도 목포과학대학교 학술연구비의 지원을 받아 연구되었음.

This study was supported by research fund Mokpo Science University, 2020

\section{REFERENCES}

1. Marques MC, González-Badillo JJ, Kluka D. In-season strength training male professional volleyball athletes. J Strength Cond Res. 2006;28(6):612.

2. Trajkovic N, Milanovic Z, Sporis G et al. The effects of 6 weeks of preseason skill-based conditioning on physical performance in male volleyball players. J Strength Cond Res. 2012;26(6):1475-80.

3. Vitale JA, Vitale ND, Cavaleri L et al. Level-and sport-specific Star Excursion Balance Test performance in female volleyball players. J Sport Med Phys Fit. 2019;59(5):733-42.

4. Olsen OE, Myklebust G, Engerbretsen L et al. Injury mechanism for anterior cruciate ligament injuries in team handball: a systematic video analysis. Am J Sport Med. 2004;32(4):1002-12.

5. Marquez WQ, Masumura M, Ae M. The effects of jumping distance on the landing mechanics after a volleyball spike. Sports Biomech. 2009;8(2):15466.

6. Silfies SP, Ebaugh D, Pontillo M et al. Critical review of the impact of core stability on upper extremity athletic injury and performance. Braz J Phys Ther. 2015;19(5):360-8.

7. Song JM, Kim SM, The effect of trunk stability exercise on balance and gait in stroke patients. Journal of Korean Society of Physical Medicine 2010:5(3): 413-20.

8. Panjabi MM. The stabilizing system of spine: part I. Function dysfunction, adaptation, and enhancement. J Spinal Disord. 1992;5(4):383-9.

9. Norris CM. Abdominal muscle training in sport. Br J Sports Med. 1993;27(1):19-27.

10. MacGill SM. Low-Back stability: from formal to issues for performance and rehabilitation. Exerc sports Sci Rev. 2001;29:23-31.

11. Sharma A, Geovinson SG, Singh SJ. Effects of a nine-week core strengthen-ing exercise program on vertical jump perform- ances and static balance in volleyball players with trunk instability. J Sports Med Phys Fitness. 2012;52(6):606-15.

12. Myer GD, Ford KR, Palumbo JP et al. Neuromuscular training improves performance and lower-extremity biomechanics in female athletes. J Strength Cond Res. 2005;19(1):51-60.

13. McGill SM, Karpowicz A. Exercises for spine stabilization: motion/motor patterns, stability progressions, and clinical technique. Arch Phys Med Rehabil. 2009;90:118-26.

14. Jang JU, Kim JH, Lee SH. Effects of lumbar stabilization exercise on balance, muscular strength in golfers with chronic low-back pain. Korean Journal of Sports Science. 2014:23(2):1409-17.

15. Cook G, Burton L, Hoogenboom BJ et al. Functional movement screening: the use of fundamental movements as an assessment of function- 
part 1. Int J Sports Phys. 2014;9(3):396-409.

16. Plisky PJ, Gorman PP, Butler RJ et al. The reliability of an instrumented device for measuring components of the star excursion balance test. $\mathrm{N}$ Am J Sports Phys Ther. 2009;4(2):92-9.

17. Shukla M, Pandey V. Relationship of core strength and isokinetic knee strength with vertical jump performance in volleyball. EJPESS. 2018:10(4):69-81.

18. Choi BG, Yoon HK. The effects of weight training and plyometric training on agility and isokinetic muscle strength. Korean Journal of Sports Science. 2013:22(1):915-22.

19. Na SH. The effects of plyometric training for 12 weeks on lower limb muscle strength, power, and agility in male college soccer players. The korean journal of growth and development. 2018:26(2):233-8.

20. Vaczi M, Tollar J, Meszler B et al. Short-term high intensity plyometric training programimproves strength, power and agility in male soccer player. J Hum Kinet. 2013:36:17-26.

21. Arokoski JP, Valta T, Airaksinen O et al. Back and abdominal muscle function during stabilization exercise. Arch Phys Med Rehab. 2001:82:1089-98.

22. Chorba RS, Chorba DJ, Bouillon LE et al. Use of a functional movement screening tool to determine injury risk in female collegiate athletes. $\mathrm{N}$ Am J Sports Phys Ther. 2010;5(2):47-54.

23. Kiesel KB, Butler RJ, Plisky PJ. Prediction of injury by limited and asymmetrical fundamental movement patterns in american football players. J Sport Rehabil. 2014;23(2):88-94.

24. Chapman RF, Laymon AS, Arnold T. Functional movement scores and longitudinal performance outcomes in elite track and field athletes. Int J Sport Physiol. 2014:9(2):203-11.

25. Yoon SD, Park GD. The effect of 8-week spinal stabilization exercise on FMS and lower extremity function in bowlers. Korean Journal of Sports Science, 2018:27(2):1167-75.

26. Jung YS. Effect of combined training on physical fitness and FMS (Functional Movement Screen) of middle school short distance athlete. Korean Journal of Sports Science. 2017:26(6):1181-91.

27. Lockie RG, Schultz AB, Jordan CA et al. Can selected functional movement screen assessments be used to identify movement deficiencies that could affect multidirectional speed and jump performance?. J Strength Cond Res. 2015:29(1):195-205.

28. Zalai D, Panics G, Bobak P et al. Quality of functional movement patterns and injury examination in elit-level male professional football players. Acta Physiologica. 2015:102(1):34-42.

29. Tori N, Susan V. Individual goniometric measurements correlated with observation of the deep overhead squat. Athl train sports health care. 2009:1(3):114-9.

30. Park JM. The effects of core balance exercises on trunk isokinetic muscular function and balance abilities and posture stability in male college volleyball player. Korean Journal of Sports Science. 2017;26(3):1077-88.

31. Choi DS, Park MH, Kim YY et al. Effects of 12-week core exercise program on isokinetic muscular function, balance and basic physical fitness of female high school volleyball players. Korean Journal of Sports Science. 2019;28(4):1251-63.

32. Noh DW, Choi HH, Lee DJ. The effects of circuit exercise program on the specific physical fitness and of exercise function improvement in university athletes. Korean Journal of Sports Science. 2019;28(3):1045-55.

33. Casselbrant ML, Furman JM, Mandel EM et al. Past history of otitis media and balance in four-year-old children. Laryngoscope. 2000;110(5):773-8.

34. Ha SM, Jeon IC. Reliability and validity of measurement using smart Phone based goniometer on pelvic tilting angle in standing and sitting position. J Kor Phys Ther. 2019;31(1):35-9.

35. Yong MS, Park SH. Leg length discrepancy to influence on kinematic changes of the pelvis and the hip during gait. J Kor Phys Ther. 2019;31 (6):368-71.

36. Lee JH, Chang JS. The effect of calf stiffness on gait, foot pressure and balance in adults. J Kor Phys Ther. 2019;31(6):346-50

37. Choi YI, Kim JS. Kim SY. Influence of Slashpipe Exercise on Symmetrical Contraction of Trunk Muscle in Normal Adults. J Kor Phys Ther. 2019;31(5):298-303.

38. Aagaard P, Simonsen EB, Magnusson SP et al. A new concept for isokinetic hamstring: quadriceps muscle strength ratio. Am J Sports Med. 1998;26(2):231-7. 